\title{
Recent developments in credit markets
}

\author{
Bernd Brommundt • Jochen Felsenheimer • \\ Philip Gisdakis • Michael Zaiser
}

Published online: 23 May 2006

(C) Swiss Society for Financial Market Research 2006

\begin{abstract}
We summarize recent developments in the credit derivative markets. We show the role of dependence between individual debtors in portfolio derivatives in a study of implied correlation. The risk of changing dependence structures between stock and bond markets becomes evident in an example of capital structure arbitrage. How credit derivatives can introduce new risks is illustrated by the example of "overlay" in basket derivatives.
\end{abstract}

Keywords Credit risk - Correlation risk - Capital structure arbitrage . Credit derivative risk

JEL Classification Numbers G13 - G33

\section{Introduction}

In recent years, the credit derivative markets have seen rapid growth in terms of the notional of contracts, reaching USD 12,400 bn in June 2005, and their liquidity. The rapid development of new products and the increase of their trading volume and liquidity have a strong impact on credit portfolio management. These instruments offer not only new investment opportunities in credit risky instruments, but also broaden the possibilities for managing credit portfolios.

\footnotetext{
B. Brommundt $(\varangle)$

Swiss Institute of Banking and Finance,

University of St. Gallen, Rosenbergstrasse 52,

9000 St. Gallen, Switzerland

e-mail: bernd.brommundt@unisg.ch

J. Felsenheimer · P. Gisdakis · M. Zaiser

HVB Corporates \& Markets,

Arabellastrasse 12, 81925 Munich, Germany
} 
In contrast to interest rate management, where the use of derivatives, in particular of swaps, is common practice, many participants in the market for credit risk still do not use credit derivatives neither for investing nor for hedging purposes. By now, actively traded instruments include single-name credit default swap contracts and (standardized) collateralized debt obligations. These allow for cost-efficient hedges of idiosyncratic and systematic risks in credit markets. Moreover, new instruments emerge: recovery default swaps allow for separating the default risk of a debtor from its recovery risk, and credit swaptions or constant maturity swaps can be used to hedge a portfolio against increasing credit risk premiums.

The advantage of credit derivatives as compared to credit risky bonds is that they are much easier to buy and sell. Especially, credit derivatives allow for an efficient implementation of short positions in the credit market, whereas short-selling a cash bond involving the repo-market is not cost-efficient.

Also, these new instruments have major implications for the active management of credit portfolios. The "old school" of credit portfolio management focused primarily on loan portfolios and thus on default risk, meaning that risk managers simply tried to avoid "bad" exposure to minimize losses stemming from occuring defaults. In a buy-and-hold context, sophisticated rating-oriented models are needed to identify the "cherries", the names that will not default, and to avoid the "lemons", the names that will default. Hence, for private loan portfolios, the major value-driver with respect to credit risk is an advanced statistical model that has high discriminative power. For commercial loans, on the other hand, fundamental balance sheet analysis with respect to the credit quality of the creditor is key. "Old school" investment strategies are mainly carry-oriented. Credit spreads generate additional income on fixed income portfolios. This approach is especially common for investors from asset and liability management who shift their investments to lower credit quality, as risk free yields decrease, to achieve the return needed by their liability side. This fundamental single-name related view ignores the cyclical nature of credit quality and correlation patterns within asset classes.

In the "new school" of credit portfolio management, default risk is not the only factor that has to be taken into account. Spread risk, which quantifies the credit-specific price component of an instrument, motivates a more active portfolio management approach. Spread changes stem from changes of the market participants' assessment of default risk, which can be either idiosyncratic or of systematic nature. As a consequence, similar management techniques as for stock portfolios are applicable to credit portfolios in liquid credit markets. In addition, the development in the securitization market enables investors and risk managers to trade even illiquid exposures such as consumer loans. Moreover, correlation patterns have to be viewed as dynamic variables rather than as static quantities, since long-term correlation patterns might decouple in the short term.

An increasing number of articles by academics and practitioners has been published on the valuation of credit-risky instruments during the last years. 
These articles tend to cover valuation methods of new innovative instruments ${ }^{1}$, credit risk modeling topics ${ }^{2}$, and especially in the recent past on new developments regarding Copula functions and approaches to adequately price correlation instruments such as collateralized debt obligations (CDOs) ${ }^{3}$.

However, there is still little literature dealing with the management of liquid credit portfolios. Credit risk modeling for single debtors is definitely a crucial part of portfolio valuation methods. However, not only the joint default probability of all instruments in the portfolio has to be understood, but also the joint spread movements. Consequently, the dependence structure between different instruments becomes increasingly important. Analyzing the impact of derivatives on a credit portfolio necessarily requires an understanding of the mechanism and price sensitivities of these instruments, especially to the "new" risk factors such as correlation changes. The strong impact of correlation changes on the prices of certain instruments is shown in the next section.

Portfolio optimization techniques experienced a lot of attention during the last decades. Improvements of the traditional portfolio selection approach tend to be the modifications of the mean-variance methodology along the lines of Black and Litterman (1992). However, the huge majority of literature is still related to the optimization process of equity portfolios, while credit portfolios, or even portfolios that include both classes of instruments are comparably neglected. The interrelation of movements in equity and debt markets is the basis of capital structure arbitrage trades, a popular hedge-fund strategy. An example of the risk from the comovement of prices in capital structure arbitrage trades is given below.

The strong growth and the increasing importance of the credit derivatives markets in terms of outstanding notional and the emerge of new products reduces transaction cost and makes markets more efficient. How credit derivatives introduce new risks, making credit portfolio management more challenging, will be the third part of our contribution.

\section{Correlation risk}

A class of credit instruments exposed to correlation risk are collateralized debt obligations (CDOs). We illustrate the role of correlation changes in a study of CDO spreads during 2005.

A CDO distributes the default losses occuring in a portfolio to a number of credit risky notes $N_{i}, i=1, \ldots, n$ according to certain well-specified rules. Typically, a note $N_{i}$ suffers all the losses in the portfolio from an attachment

\footnotetext{
1 See, for example, the books by Ammann (2001), Schönbucher (2003), or Bielecki and Rutkowski (2002).

2 See, for example, Giesecke (2004) or Brigo and Errais (2005).

3 E.g. Li (2000), Hull and White (2005); see Burtschell et al. (2005) for an presentation of CDO valuation models and Finger (2005) for an overview of open research questions.
} 
level $K_{i-1}$ up to a detachment level $K_{i}$. Andersen and Sidenius (2005) give an overview of CDO pricing models.

Today, most generally accepted approaches to CDO pricing are from the class of copula models and often written in the form of a factor model [see, for example, Burtschell et al. (2005)]. The free parameters in the models used to calibrate it to market prices are the dependence parameters, the correlations between the price driving factors. Since the underlying portfolio of a CDO might easily contain hundreds of different debtors, a huge number of parameters theoretically enters into the CDO pricing model. In order to simplify and speed up calculations, it is common to assume a constant default probability for all and a constant dependence structure between all debtors in the portfolio. This simplification reduces the number of parameters used to calibrate the model to market prices to two, which practically eliminates the possibility to calibrate the model to different tranche prices. However, market participants have begun quoting the model implied correlation for each tranche as a means to communicate prices. McGinty et al. (2004) suggest to calculate the implied correlations in a specific way, which they refer to as "base-correlations": For a specific CDO they aggregate tranches consecutively to obtain synthetic tranches with attachment at 0 and detachment at the respective detachment points of the tranches. The values of these synthetic first loss tranches are then calibrated to market spreads successively starting from the tranche with the lowest detachment level. Even though this basic procedure is accepted among market participants, individual model specifications can lead to large price deviations. Thus, also implied correlations, which can strongly depend on the model specification, disperse.

In the context of CDO pricing, implied correlations take a similar role as implied volatilities for option prices: for a given model, they constitute a different way to quote prices. However, the role of correlation risk in the pricing of portfolio credit derivatives is not so well-understood. We will illustrate the importance of correlation changes in the following example.

\subsection{The correlation crisis}

The CDO we consider here is the iTraxx S3 CDO. The underlying portfolio of credit risky instruments is the iTraxx CDS index. It consists of the 125 most actively traded CDS contracts on European companies. We investigate the first two tranches, equity and mezzanine, of this CDO with attachment-detachment levels of 0 and $3 \%$, and 3 and $6 \%$, respectively.

In the first quarter of 2005, hedge funds and proprietary trading desks of banks entered long positions in the equity tranche (attachment-detachment $0-3 \%$ ) of the ITraxx CDO while shorting the mezzanine tranche (attachmentdetachment $3-6 \%$ ). The motivation for this trade was the expectation that credit spreads would remain relatively stable in 2005. Thinking in "old school" dimensions, these trading positions generated positive carry. Moreover, most trades were structured to be delta-neutral (meaning they were immune against systematic spread moves), thus also taking into account some "new school" ideas. 
However, these positions had an exposure to changes in portfolio correlation. The evolution of spreads on the index and on the mezzanine tranche is displayed in Figure 1; that of the mezzanine tranche and the equity tranche in Figure 2. Note that the iTraxx equity tranche is not quoted as a quarterly spread but as an advance payment relative to the tranche notional. We can see that the spread on the mezzanine tranche declines during the observation period, while the upfront payment on the equity tranche peaks in May 2005 and is relatively

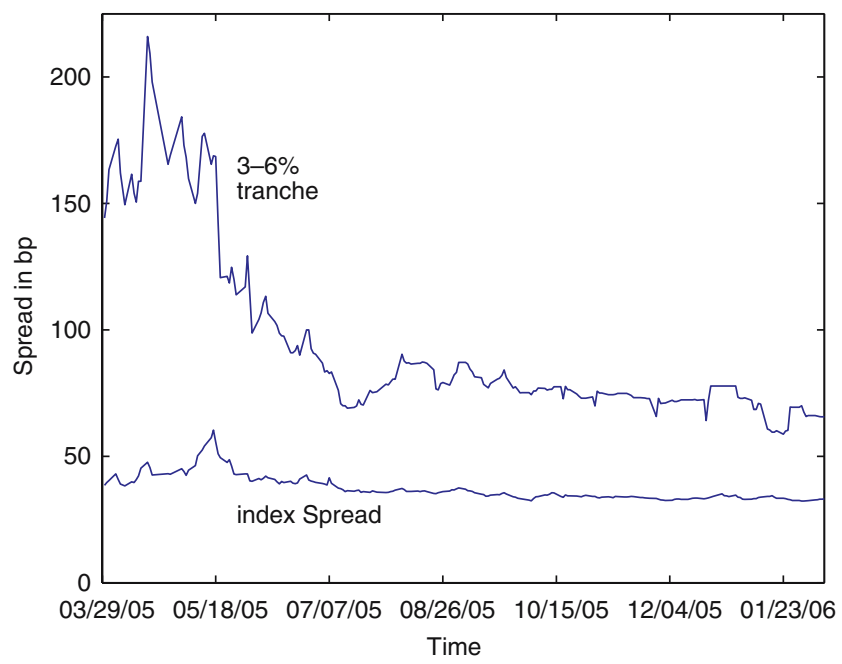

Fig. 1 Evolution of the iTraxx index and of the 3-6\% tranche of the iTraxx S3 CDO tranche. Data Source: Bloomberg, HVB Global Markets Research
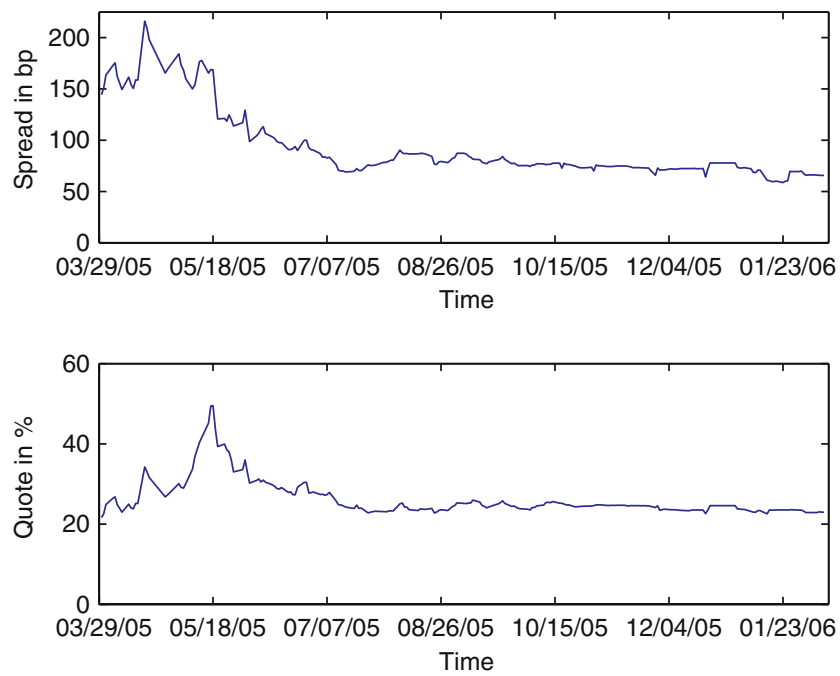

Fig. 2 Top: Evolution of the iTraxx S3 3-6\% spread, Bottom: evolution of the iTraxx S3 equity tranche spread. Data Source:Bloomberg, HVB Global Markets Research 
stable at about $25 \%$ for the rest of the time. The spreads on the iTraxx index are relatively stable at around 40 basis points (bp), with the exception of May 2005 when they rise to about $60 \mathrm{bp}$ for a short period of time, triggering the so called "correlation crises". We want to point out the falling spread on the mezzanine tranche during 2005 in contrast to the stable index spreads. The increase in index spreads in May 2005 was driven only by a couple of names and thus was accompanied by an increase in the dispersion of credit spreads between different debtors in the index.

To quantify this effect and to relate it to the correlation implied in market spreads, we use the large homogeneous portfolio approximation (LHP) suggested by Vasicek (1977).

The underlying assumptions of the LHP are a constant identical default probability for all debtors in the portoflio and a constant identical correlation between all debtors. We clarify the meaning of correlation in this context below. Today, the LHP would be characterized as a (one-factor) Gaussian Copula model.

We obtain an estimate for the default probability from the premium of a hypothetical CDS contract. The price of such a contract is quoted as the spread $s$ which makes the expected value of the premium side of the contract equal to the expected value of the protection side. We assume that the contract is priced at $t_{0}=0$ and the times of premium payments are $t_{1}, \ldots, t_{T}$. In the case of default, which we assume to happen immediately before the $t_{i}$, the seller of the contract suffers a loss of $L=60 \%$. The pricing equation now reads:

$$
L \sum_{i=1}^{T} \mathrm{e}^{-r_{i} t_{i}} \boldsymbol{P}\left(\text { default in }\left(t_{i-1}, t_{i}\right]\right)=s \sum_{i=1}^{T} \mathrm{e}^{-r_{i} t_{i}} \boldsymbol{P}\left(\text { default after } t_{i}\right)
$$

where the periodic CDS spread $s$ on the premium side is chosen to satisfy the equation; the interest rates $r_{t}$ are assumed to be known. The default probability can be written as $\boldsymbol{P}$ (default before $t$ ) $=1-e^{-\lambda t}$. Entering this in (1), we can solve for

$$
\lambda=-\frac{1}{\Delta t} \ln \left(\frac{0.6}{0.6+s}\right)
$$

We used the spread $s$ of the iTraxx index on each day during the sample period to obtain an estimate for $\lambda$ and thus for the default probabilities.

In the LHP default of a company $i$ occurs when a latent variable, e.g., the firm value, falls below a specified level, e.g., the value of debt. This factor is written as

$$
X_{i}=\alpha M+\sqrt{1-\alpha^{2}} W_{i},
$$

where $M$ is a standard normally distributed common factor to all companies and $W_{i}$ is an idiosyncratic factor for each company, which is also standard normal. 
The correlation between the latent variables of any two debtors is assumed to be fully captured by the common factor and is $\alpha^{2}$. This correlation is the correlation we will solve later. Using this factor for a given default probability the default barrier can be found. Calculating the default probabilities conditional on a realization of the common factor and assuming an infinite number of obligors in the portfolio, Vasicek (1977) obtains the distribution for the relative loss of the portfolio. From this distribution the expected losses on CDO tranches can be calculated. Using these, the pricing equation for the CDO tranche with attachment point $K_{i-1}$ and detachment point $K_{i}$ is similar to that of the CDS:

$$
\begin{array}{r}
\sum_{i=1}^{T} \mathrm{e}^{-r_{i} t_{i}}\left(E L_{K_{i-1}, K_{i}}\left(t_{i}\right)-E L_{K_{i-1}, K_{i}}\left(t_{i-1}\right)\right)= \\
s \sum_{i=1}^{T} \mathrm{e}^{-r_{i} t_{i}}\left(1-E L_{K_{i-1}, K_{i}}\left(t_{i-1}\right)\right),
\end{array}
$$

where $E L_{K_{i-1}, K_{i}}(t)$ denotes the expected loss for the tranche for a time horizon $t$.

We apply this formula to market prices and extract the correlation parameter implied in prices of the equity and the 3-6\% tranche for daily data from March 2005 to January 2006. The results are displayed in Figure 3. Even though this simple model and estimation procedure neglect parameter dynamics, it can illustrate the changes of implied correlation over time. Implied correlations of the two tranches comove over the entire sample. From March to mid-May 2005, the implied correlation of the equity tranche drops from around $30 \%$ to around $12 \%$; that of the $3-6 \%$ tranche drops from around $10 \%$ close to $0 \%$. This drop

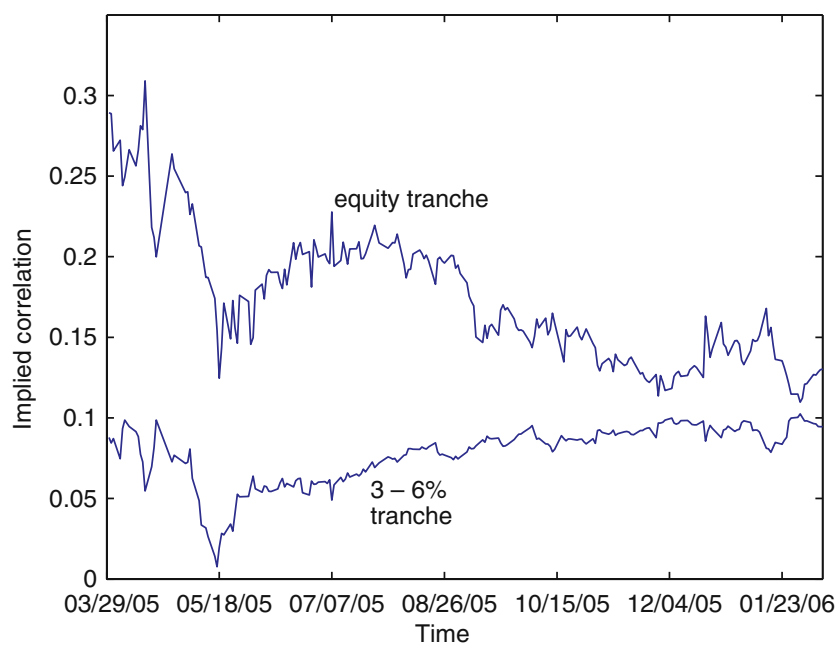

Fig. 3 Top: Evolution of the iTraxx S3 3-6\% implied correlation, Bottom: evolution of the iTraxx S3 equity tranche implied correlation 
is called the correlation crisis. After the drop, correlations on both tranches increase again with the correlation for the equity tranche trading around $15 \%$ and that of the mezzanine tranche at around $10 \%$, which roughly is the pre-crisis level.

The influence of correlations on the tranche values is not the same across tranches: while the spread on the mezzanine tranche decreases (value increases) as the correlation declines, the equity tranche upfront payment increases (value decreases) as implied correlation rises. This is because the value of the equity tranche is determined by losses between 0 and $3 \%$ of the portfolio. The probability of these increases as the correlation declines. Conversely, the probability of losses affecting the mezzanine tranches of a CDO generally increases as the correlation increases. Thus, the rapid decline of implied correlation from March to mid-May 2005 indicates a rapid increase in the value of the 3-6\% tranche and a decrease of the value of the equity tranche, as illustrated in Figure 2.

To illustrate the importance of correlation risk we want to stress that individual CDS spreads (and default risk) increase by around $50 \%$ in the crisis. Naively thinking, one would thus have expected increasing spreads for all tranches.

As a consequence of the price movements, the trading positions described suffered big losses. Moreover, many of these positions were held by hedge funds which were highly levered. These trades had to be unwound as collateral was exhausted and brought some funds to the edge of bankruptcy.

In the aftermath of the "correlation crisis" a discussion about a possible modification of the standard Gaussian copula model emerged. However, the trigger for this crisis was not a failure of the models used but rather a speculative bet on the wrong side of the market.

Even though the role of implied correlation is similar to that of implied volatility, it is difficult to quantify a premium for correlation risk. It is hardly possible to observe realized correlation since the model is based on latent processes. A more detailed discussion of open questions in CDO pricing from is Finger (2005). An approach for estimating correlation risk is undertaken in Albanese et al. (2005).

\section{Capital structure arbitrage}

The class of structural models in the line of Merton (1974) is the basis of strategies of trading simultaneously in debt and equity markets. These so-called capital structure arbitrage strategies are popular among hedge funds. The idea is to exploit pricing anomalies between different instruments of the same issuer, say stocks, stock options, and credit risky instruments. Theoretically, a structural model, given all relevant parameters, allows to price all these instruments in a consistent, arbitrage-free way. Besides calibration issues, empirical tests such as recently by Eom et al. (2004) show that models, calibrated to equity market prices and debt markets, tend to underestimate the credit spreads for debtors of lower quality and to overestimate the spread for debtors of higher quality. This is frequently seen as a drawback of structural models. Henrotte (2006) 
argues that there is the possibility of sudden dramatic changes in the capital structure of a company because of the possibility of a leveraged-buy-out or because of takeovers of or by other firms. In spite of all these shortcomings, the class of structured form models is generally accepted as reasonably describing the interrelations between different financial instruments among academics and practitioners.

A prominent and recent example for capital structure arbitrage trades are the debt/equity trades on General Motors (GM), one of the largest issuers of corporate bonds in the US. The trades involved stock, stock options, bonds, and CDS and we investigate the period of early 2005. Despite an anticipated downgrade of the issuer, GM bonds offered spreads considered as attractive by many in that period. Thus, speculators entered into a long position in GM bonds, which they hedged by short positions in GM stocks. Some market participants substituted the short equity position with a long volatility position using GM options. The rationale of the trade was based on the assumption that a spread increase would be accompanied by a drop in stock prices or an increase in implied option volatility. The relative size of the trading positions were determined by the use of structural models.

In structural models equity value and the default probability are basically determined by the ratio of debt to firm value and by firm value volatility. While the value of equity can be observed directly, the volatility and the debt have to be estimated either from historical data or implied quantities can be extracted from market prices. The evolution of the GM stock market capitalization of the implied volatility from put options and of the 5-year CDS spread is displayed in Figure 4. Most of the time CDS spread declines as the capitalization of GM

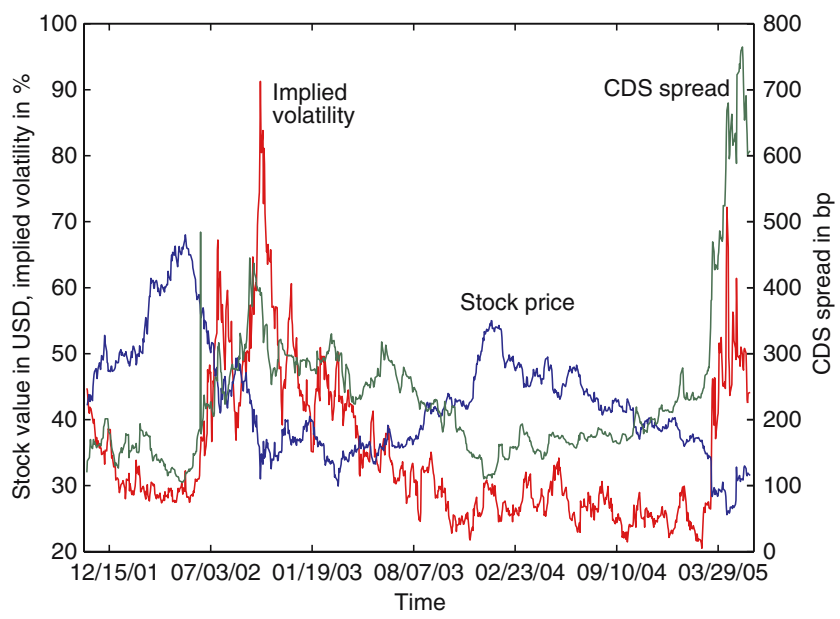

Fig. 4 The market capitalization of GM (left scale), the 5-year CDS spread (right scale), and the put-option implied volatility (left scale) principally show the behavior that is expected from structural models. The rapid changes of all series in the last (marked) part of the sample period, however, has a strong impact on trading positions. Data Source: HVB Global Markets Research 
stocks increases and the CDS spread rises when volatility rises as described by structured form models. However, in the last part of the sample all three quantities change drastically. Especially, implied volatility fluctuates rapidly. A reason for this could be a restructuring of GM debt becoming more probable. Restructuring is a credit event in CDS contracts and has an unclear effect on share prices. Thus, a more probable restructuring introduces more uncertainty into prices.

The rapid movements lead not to a breakdown of the structured form models but forced large adjustments of the relative sizes of trading positions. Since many market participants were forced to adjust their positions at the same time, this amplified market movements. Several capital structure arbitrage desks that suffered dramatic losses had to close out their positions.

The case of GM is also studied by Finger and Stamicar (2005) who extract the debt-per-share value from GM stockprices, option prices, and CDS quotes using their CreditGrades model from accounting data and from market prices. As suggested by Hull et al. (2004/2005) they find a higher explanatory power if they use option implied quantities to calibrate their model.

\section{New risks from credit derivatives}

The strong growth of the credit derivatives market in terms of the outstanding amount of notional as well as regarding the product development is accompanied by a shift in the basic incentive to use credit derivatives, and also has a strong impact on pricing issues. According to Fitch (2005), trading rather than hedging has become the major incentive to use credit derivatives in the global banking sector. This means that the holding periods decline on average, causing rising spread volatility and creating additional demand for hedging instruments, thus leading to a further growth of the credit derivative market. In any case, (credit) derivative instruments increase transparency and efficiency in the market, but can also induce new risks through rising leverage which can lead to increasing volatility in case credit events. In addition, the deviating growth in credit derivative and cash bond markets can lead to a mismatch between derivative (notional) and actual cash positions for specific reference entities.

This mismatch was highlighted in the aftermath of the chapter 11 filing of US auto supplier Delphi on 8 October 2005. Outstanding cash bonds with a notional of USD 2 bn faced an outstanding protected volume of notional in indices, synthetic CDOs, and single name CDS of around USD $10 \mathrm{bn}$. As physical settlement is the market standard for single-name CDS and credit indices, many market participants who did not have the reference obligations on their books had to buy them to settle their contracts in a default case. This excessive demand for Delphi bonds propelled up prices ("short squeeze"), even though these higher levels did not adequately reflect the economic loss. While Delphi bonds were quoted at a cash-level of $57 \%$ shortly after filing for bankruptcy, prices of distressed debt recovered to around $70 \%$ in late October and early November 2005 on the back of concerns about a paper shortage. Market 


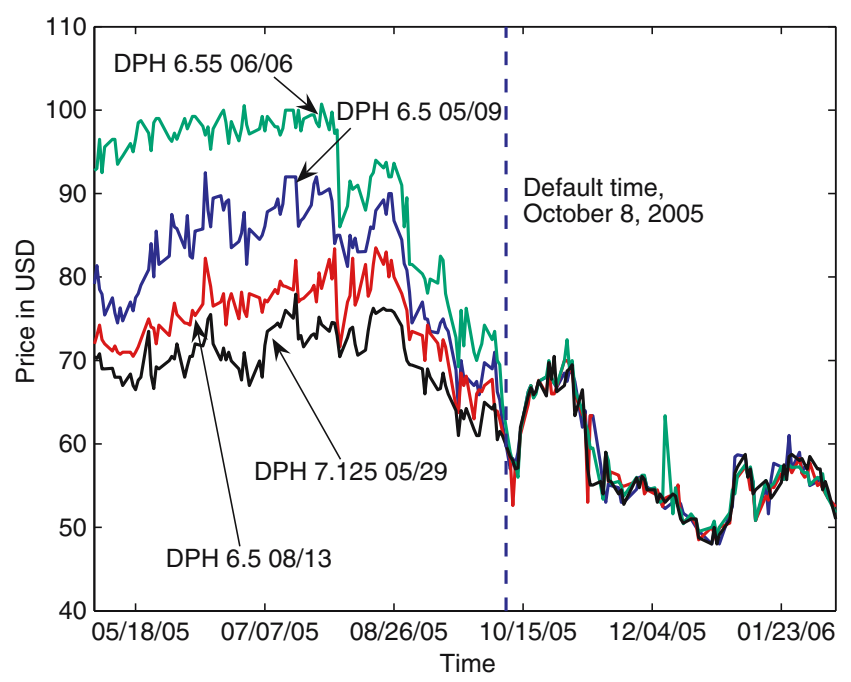

Fig. 5 The prices of four bonds issued by Delphi. Data Source: Bloomberg, HVB Global Markets Research

participants cleared this situation by arranging an auction to determine reference prices for Delphi bonds. On 4 November 2005, this auction-determined price was USD 63.375 per USD 100 of notional. After the auction, Delphi bonds traded between USD 50 and USD 60. The price movement is shown in Figure 5.

The Delphi case is an example for the strong impact of credit derivatives on the market pricing of credit-risky instruments. The situation when derivative notional is larger than actual debt is referred to as "overlay" in the CDO business. It occurs because many CDO transactions are driven by "rating arbitrage": $\mathrm{CDO}$ arrangers prefer the names that pay the highest spreads in a specific rating class. Since the number of issuers whose market implied rating deviates significantly from that of a rating agency is limited, overlay in the CDO market is seen frequently.

Because of overlay, the market impact from single-name defaults has changed from a pure idiosyncratic nature to a more systematic nature. This can be seen as a new risk which caused by credit derivatives. Thus, the strong growth of the credit derivatives market leads not only to new investment and hedging opportunities but also to the emergence of new risk factors. These new factors in turn force portfolio managers to implement a more active management style.

\section{Conclusion}

The market for credit derivatives has seen a rapid growth in recent years in terms of outstanding volume of notional and liquidity. New products offer new opportunities to investing, hedging, and trading in credit markets. However, as markets become more liquid and transparent, the important role of 
dependence becomes even more evident. We show that correlations implied in credit portfolio derivatives changes significantly over time and strongly impacts market prices. Moreover, we illustrate the crucial role of the understanding of dependence structures between stock and bond markets in capital structure arbitrage trades. A direct dependence through "overlay" illustrates that new risks can emerge through developments in credit derivative markets. We believe that increasing liquidity in credit derivative markets will allow both academics and practitioners to further investigate and understand the (joint) behavior of price movements in debt and equity markets.

Acknowledgements The authors would like to thank Manuel Ammann (the editor) for helpful comments and Jan Peter Kulak for valuable research support.

\section{References}

Albanese, C., Chen, O., Dalessandro, A.: Dynamic credit correlation modeling. Working Paper, Imperial College London (2005)

Ammann, M.: Credit Risk Valuation, vol. 1 of Springer Finance, 2nd edn. Springer, Berlin, Heidelberg, New York (2001)

Andersen, L., Sidenius, J.: Cdo pricing with factor models: survey and comments. J. Credit Risk 1(3): $71-88$ (2005)

Bielecki, T. R., Rutkowski, M.: Credit Risk: Modeling, Valuation and Hedging, Springer Finance, 1st edn. Springer, Berlin, Heidelberg, New York (2002)

Black, F., Litterman, R.: Global portfolio optimization. Financ Analysts. J. 48, 28 - 43 (1992)

Brigo, D., Errais, E.: A correlation bridge between structural models and reduced form models for multiname credit derivatives. Working Paper, Stanford University (2005)

Burtschell, X., Gregory, J., Laurent, J.P.: A comparative analysis of cdo pricing models. Working Paper, University of Lyon (2005)

Eom, Y.H., Jean, H., Huang, J.-Z.: Structural models of corporate bond pricing: an empirical analysis. Rev. Financ. Stud. 17: 499 - 544 (2004)

Finger, C.: Issues in the pricing of cdos. J. Credit Risk 1(1): 113 - 123 (2005)

Finger, C., Stamicar, R.: Better ingredients. J. Credit Risk 1(3): 89 - 97 (2005)

Fitch: Global derivatives survey. Fitch Rating, Special Report (2005)

Giesecke, K.: Credit risk modeling and valuation: an introduction. In: Shimko, D. (ed.) 'Credit Risk: Models and Management', vol. 2, pp. 487 - 526. Risk Books (2004)

Henrotte, P.: Modeling issues in the equity to credit universe. Working Paper, Presented on the Hybrid Conference, London (2006)

Hull, J., White, A.: The perfect copula. Working Paper, University of Toronto (2005)

Hull, J.C., Nelken, I., White, A.D.: Merton's model, credit risk and volatility skews. J. Credit Risk 1(1): 3 - $27(2004 / 2005)$

Li, D.X.: On default correlation: a copula function approach. J. Derivatives 43-54 (2000)

McGinty, L., Beinstein, E., Ahluwalia, R., Watts, M.: Introducing base correlations. JPMorgan, Credit Derivatives Strategy (2004)

Merton, R.C.: On the pricing of corporate debt: the risk strucutre of interest rates. J. Finance 29(2): $449-470$ (1974)

Schönbucher, P.: Credit Derivatives Pricing Models. Wiley, Chichester (2003)

Vasicek, O.A.: An equilibrium characterization of the term structure. J. Financ. Econ. 5: 177 - 188 (1977) 


\section{Author's Biography}

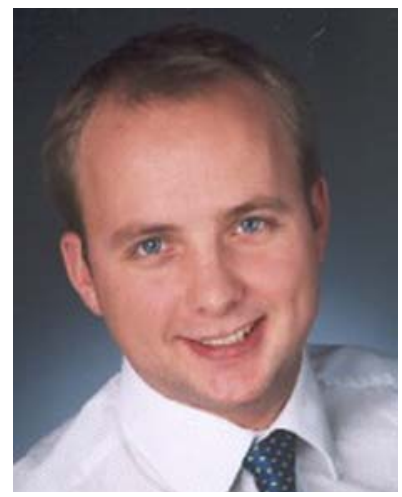

Bernd Brommundt is a PhD student at the University of St. Gallen. He works as a research and teaching assistant at the Swiss Institute of Banking and Finance. His research interests are in credit risk modelling and credit portfolio derivatives. Bernd graduated from Munich University of Technology with a Master's Degree in Financial Mathematics and Economics in 2003 .

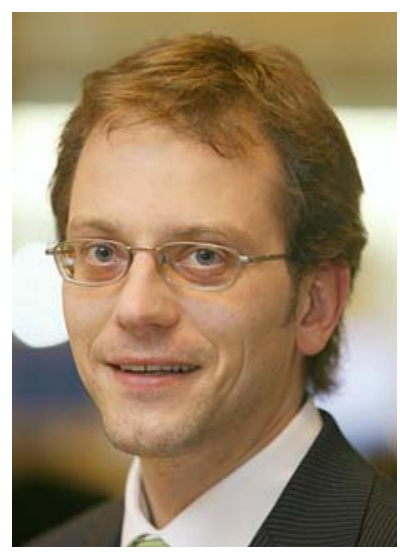

Jochen Felsenheimer is Head of the Credit Credit Derivatives Strategy team of HVB Corporates Markets in Munich since March 2004. Formerly, he worked as a Research Strategist and was responsible for Relative Value Analysis of Corporates and Credit Derivatives, as well as for Construction and Optimization of portfolios. Prior to joining Hypovereinsbank, Jochen had his own business, trading plain-vanilla derivatives. Jochen holds a $\mathrm{PhD}$ in Economics from Munich University and is co-author of the book Active Credit Portfolio Management, Wiley, 2005.

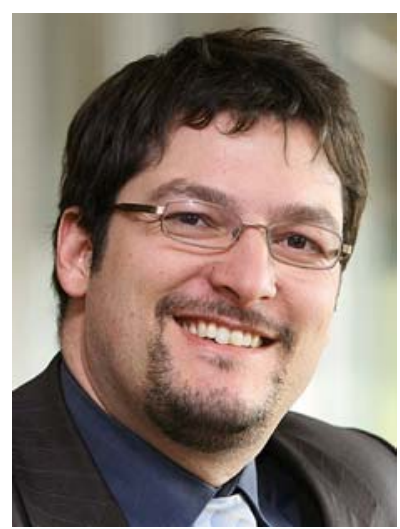

Philip Gisdakis is a Quantitative Credit Strategist with HVB Corporates Markets in Munich. The focus of his work is in the credit derivative sector and credit portfolio advisory. Before Philip joined HVB, he worked as a Senior Risk Consultant for d-fine GmbH. Philip studied Mathematical Finance at the University of Oxford and holds a $\mathrm{PhD}$ in Theoretical Chemistry from Munich University of Technology. He is co-author of the book Active Credit Portfolio Management, Wiley, 2005. 


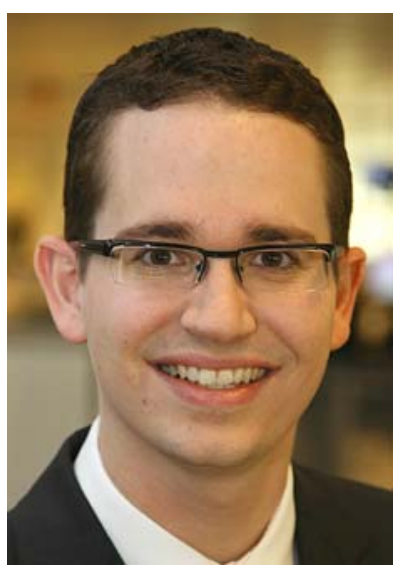

Michael Zaiser is a Credit Strategist in the Credit Credit Derivatives Strategy team of HVB Corporates Markets in Munich. He joined HVB in 2002, working as a financial accountant (German-GAAP and IAS/IFRS) and was promoted to the Credit Strategy team in July 2004. Michael holds a degree in Business Administration from the Johann Wolfgang Goethe University, Frankfurt. He co-authored the book Active Credit Portfolio Management, Wiley, 2005. 